\title{
Influence of hydrotalcite preparation conditions on its physico-chemical properties
}

\author{
Miroslava Mališováa, Michal Horňáček ${ }^{a}$, Pavol Hudec ${ }^{a}$, \\ Jozef Mikulec $^{\mathrm{b}}$, Vladimír Jorík ${ }^{\mathrm{c}}$, Elena Hájeková \\ ${ }^{a}$ Department of Organic Technology, Catalysis and Petroleum Chemistry, \\ Faculty of Chemical and Food Technology, Slovak University of Technology, \\ Radlinského 9, 81237 Bratislava, Slovakia \\ ${ }^{b}$ Research Institute of Petroleum and Hydrocarbon Gases, Vlčie Hrdlo, 82003 Bratislava, Slovakia \\ ${ }^{c}$ Department of Inorganic Chemistry, Faculty of Chemical and Food Technology, \\ Slovak University of Technology, Radlinského 9, 81237 Bratislava, Slovakia \\ mamiroslava@gmail.com
}

\begin{abstract}
The aim of the research was to prepare and characterize hydrotalcite synthesized under different preparation conditions. The most common hydrotalcite preparation is the co-precipiaton method. The preparation process strongly influences the catalytic properties of hydrotalcite; therefore, optimal conditions have to be determined. During the study, seven samples of the catalyst were prepared in the $\mathrm{pH}$ range from 8 to 12 and the synthesis temperature range from 25 to $55^{\circ} \mathrm{C}$. Based on several catalyst properties, optimal synthesis $\mathrm{pH}$ 10 was found. Ideal temperature of the preparation was determined to be $35^{\circ} \mathrm{C}$, but the temperature does not have a significant effect on the catalyst properties.
\end{abstract}

Key words: hydrotalcite, preparation conditions, co-precipitation, catalyst

\section{Introduction}

Several types of layered double hydroxides (LDH) were studied for various applications depending on their crystallinity and catalyst properties. LDH synthesis dates from 1930, when precipitation was used to prepare samples (Sato et al., 1988). A wide range of applications of this special layered structure have been studied. For example, oil adsorbents, sorption agents for industrial, sensors in electrochemistry and flame retardants in polymer nanocomposites (Cavani et al., 1991, Salomão et al., 2013).

Hydrotalcite (HT) belongs to the group of LDH, also known as anionic clays. In comparison to cationic clays, anionic clays are not very common in nature but their preparation in laboratory is much easier. The most widely used HT is magnesium-aluminum type with the chemical formula $\left[\mathrm{M}_{\mathrm{n}}{ }^{2+} \mathrm{M}_{\mathrm{m}}{ }^{3+}(\mathrm{OH})_{2(\mathrm{n}+\mathrm{m})}\right]_{\mathrm{m}}{ }^{+}\left[\mathrm{A}_{\mathrm{x}}{ }^{-}\right]_{\mathrm{m} / \mathrm{x}}{ }_{\mathrm{y}} \mathrm{H}_{2} \mathrm{O}$, where $\mathrm{M}^{2+}$ and $\mathrm{M}^{3+}$ are divalent and trivalent metal cations and $A_{x}$ is the interlayer anion. An identical formula was found for the natural mineral hydrotalcite (Nishimura et al., 2013). Layered structure is based on rotation of positively charged octahedral layers and interlayer space. Charge balancing anions and water molecules occupy the interlayer space (Baskaran et al., 2015). The range of metal cations from the positive charge layer is relatively wide and is determined by their size, which should be similar to that of $\mathrm{Mg}^{2+}$ for divalent cations and that of $\mathrm{Al}^{3+}$ for trivalent cations (Basag et al., 2016).
Scheme 1 shows a simplistic representation of the hydrotalcite structure (Baskaran et al., 2015).

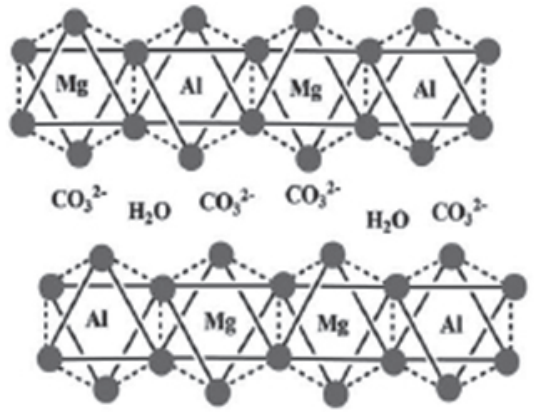

Scheme 1. Simplistic representation of hydrotalcite structure (Baskaran et al., 2015).

\section{Synthesis}

Co-precipitation is the most common method to prepare LDH like hydrotalcite. There are two different way of preparation: co-precipitation at variousable $\mathrm{pH}$ and at constant $\mathrm{pH}$ values. At constant $\mathrm{pH}$, preparation is based on addition of $\mathrm{NaOH}$ solution to maintain the $\mathrm{pH}$ value constant during the whole time of preparation. In the variable $\mathrm{pH}$ method, a solution containing salts of the cations (divalent and trivalent) is added to an alkaline solution containing the anion to be interlayered. With the increasing concentration of alkaline metals, $\mathrm{pH}$ decreases. Co-precipitation is usually carried out at relatively low temperatures, usually up to $55^{\circ} \mathrm{C}$, 
to prevent secondary formation reaction of simple hydroxides (Salomão R, et al., 2013).

\section{Hydrotalcite application}

Thanks to its special layered structure, hydrotalcite can be used for a variety of applications such as base, redox and photo-catalyst, as well as adsorbents. As a base catalyst, hydrotalcite can catalyze a wide range of reactions such as aldol condensation, hydroxylation, isomerization and others. Nowadays, many studies deal with hydrotalcite use as an adsorbent to reduce emissions of $\mathrm{NO}_{\mathrm{x}}$ and $\mathrm{SO}_{\mathrm{x}}$ because of its large sorption capacity. Hydrotalcite has drawn attention also as a catalyst to produce biofuels as it is very effective for transesterification of vegetable oils to produce biofuels. Easy preparation by coprecipitation, which is quick and not complicated, as well as its great catalyst properties are its advantage.

\section{Experimental}

One of the most common methods to prepare hydrotalcite was used to prepare seven samples. First solution (A) was $\mathrm{Na}_{2} \mathrm{CO}_{3}\left(\mathrm{c}=0.5 \mathrm{~mol} / \mathrm{dm}^{3}\right)$ dissolved in $1 \mathrm{~L}$ of deionized water. Solution of metal nitrates (solution $\mathrm{B}$ ) prepared from $\mathrm{Mg}\left(\mathrm{NO}_{3}\right)_{2}$ and $\mathrm{Al}\left(\mathrm{NO}_{3}\right)_{3}$ with the concentration of $1.0 \mathrm{~mol} / \mathrm{dm}^{3}$ was slowly added $(10,44 \mathrm{ml} / \mathrm{min})$ to solution A for 1 hour. Preparation of hydrotalcite samples was realized in the $\mathrm{pH}$ range from 8 to 12 and temperature range from 25 to $55^{\circ} \mathrm{C}$. The $\mathrm{pH}$ value was kept constant by addition of $\mathrm{NaOH}$ solution with the concentration $\mathrm{c}=3.0 \mathrm{~mol} / \mathrm{dm}^{3}$. Addition of $\mathrm{NaOH}$ was controlled by a $\mathrm{pH}$ electrode measuring the $\mathrm{pH}$ value throughout the reaction. Temperature was monitored by a temperature sensor connected to a heating plate. Each sample aged for 24 hours. After the solution sedimentation, the sediment was washed with at least $2 \mathrm{~L}$ of distilled water and filtered. Drying was carried out for 1-2 hours at $80^{\circ} \mathrm{C}$. After the preparation, all samples were stored in an airtight container and subsequently calcined at $150{ }^{\circ} \mathrm{C}$ and $450{ }^{\circ} \mathrm{C}$. Prepared samples were used for further measurements.

Crystalline phase identification and phase purity determination of the prepared samples were carried out by XRD analysis using a STOE THETATHETA diffractometer, with CoK $\alpha$ radiation, scan range of $2.90^{\circ}-90.00^{\circ} 2 \Theta$ and at the step size of $0.02^{\circ}$.

Surface characteristics were measured by physical adsorption of nitrogen at $-196{ }^{\circ} \mathrm{C}$ using ASAP2400 (Micromeritics). Overnight evacuation of the samples at $150{ }^{\circ} \mathrm{C}$ and $450{ }^{\circ} \mathrm{C}$ preceded the adsorption analysis. Specific surface area, $S_{\mathrm{BET}}$, was obtained using the conventional BET isotherm $\left(\mathrm{p} / \mathrm{p}_{0}=0.05-0.30\right)$. The surface of mesopores, $S_{t}$, and the volume of micropores, $\mathrm{V}_{\text {micro, }}$, were calculated from the t-plot using the Harkins-Jura master isotherm. The value of the total pore volume, $V_{a}$, was determined from adsorption data at relative pressure $\mathrm{p} / \mathrm{p}_{0}=0.99$. From desorption branches of the isotherms, pore size distribution was calculated using the BJH method.

Temperature programmed desorption of carbon dioxide as a probe molecule (TPD- $\mathrm{CO}_{2}$ ) was carried out in equipment with a TCD detector. The catalyst amount of $200 \mathrm{mg}$ (grain of $0.4-0.71 \mathrm{~mm}$ ) was placed in a quartz reactor. Before the TPD experiment, the catalysts were activated at $450{ }^{\circ} \mathrm{C}$ for 80 minutes in helium flow $(75 \mathrm{~mL} / \mathrm{min})$. Subsequently, the catalysts were cooled down to $25^{\circ} \mathrm{C}$ and treated with $\mathrm{CO}_{2}$ flow (99\% purity, $50 \mathrm{~mL} / \mathrm{min}$ ) for 30 minutes. The weakly adsorbed $\mathrm{CO}_{2}$ was removed by flushing the sample with helium $(110 \mathrm{~mL} / \mathrm{min})$ at $25{ }^{\circ} \mathrm{C}$ for 80 minutes. Desorption of $\mathrm{CO}_{2}$ was measured by heating the catalyst from $25{ }^{\circ} \mathrm{C}$ to $500{ }^{\circ} \mathrm{C}$ at the heating rate of $5^{\circ} \mathrm{C} / \mathrm{min}$ in helium flow. The amount of basic sites was calculated from the area of $\mathrm{CO}_{2}$ desorption peaks with help of calibration using a known amount of $\mathrm{CO}_{2}$ desorbed from $\mathrm{MgCO}_{3}$ decomposition.

SEM images were taken using field emission JEOL JSM-7600F SEM at the accelerating voltage of $5 \mathrm{kV}$ and working distance of $4.5 \mathrm{~mm}$.

\section{Result and Discussion}

Seven samples of aluminum-magnesium hydrotalcite were prepared for the study under various synthesis conditions. Temperature of the synthesis as well as $\mathrm{pH}$ were varied for each sample. Table 1 presents symbols of individual samples together with their preparation conditions. All samples were prepared with the same amount of metal nitrates and $\mathrm{Na}_{2} \mathrm{CO}_{3}$ solution.

Tab. 1. Samples preparation conditions.

\begin{tabular}{lcc}
\hline Sample & $\begin{array}{c}\text { pH } \\
\text { of synthesis }\end{array}$ & $\begin{array}{c}\text { Temperature of synthesis } \\
{\left[{ }^{\circ} \mathbf{C}\right]}\end{array}$ \\
\hline HTT/10/25 & 10 & 25 \\
HTT/08/25 & 8 & 25 \\
HTT/09/25 & 9 & 25 \\
HTT/12/25 & 12 & 25 \\
\hline HTT/10/45 & 10 & 45 \\
HTT/10/55 & 10 & 55 \\
HTT/10/35 & 10 & 35 \\
\hline
\end{tabular}


Temperature was controlled by means of a temperature sensor connected to a heating plate while $\mathrm{pH}$ was maintained at a constant value during the reaction by $\mathrm{NaOH}$ solution. Designation of the samples was as follows: HTT/pH/temperature.

\section{Specific surface area - BET}

One of the most important properties of a catalyst is its specific surface area. It tells us about the catalyst adsorption capability. With the increasing specific surface area, hydrotalcite gains better properties for the catalysis of various reactions.

The determined specific surface areas of samples calcined at $150{ }^{\circ} \mathrm{C}$ and $450{ }^{\circ} \mathrm{C}$ with different preparation $\mathrm{pH}$ can be seen in Table 2 . HTT/10/25 prepared at $\mathrm{pH} 10$ shows the highest specific surface area and pore volume at both calcination temperatures.

A graphical comparison of the samples prepared at $25^{\circ} \mathrm{C}$ and calcined at $150{ }^{\circ} \mathrm{C}$ and $450{ }^{\circ} \mathrm{C}$ with different $\mathrm{pH}$ can be seen in Figure 1. A significant increase in the specific surface area for the sample prepared at $\mathrm{pH} 10$ can be observed.
Tab. 2. Determined surface area of samples with different preparation $\mathrm{pH}$.

\begin{tabular}{lcccc}
\hline \multirow{2}{*}{ Sample } & \multicolumn{2}{c}{$\mathbf{1 5 0}{ }^{\circ} \mathbf{C}$} & \multicolumn{2}{c}{$\mathbf{4 5 0}{ }^{\circ} \mathbf{C}$} \\
\cline { 2 - 5 } & $\begin{array}{c}\mathbf{S}_{\text {BET }} \\
{\left[\mathbf{m}^{2} / \mathbf{g}\right]}\end{array}$ & $\begin{array}{c}\mathbf{V}_{\mathbf{a}} \\
{\left[\mathbf{c m}^{3} / \mathbf{g}\right]}\end{array}$ & $\begin{array}{c}\mathbf{S}_{\text {BET }} \\
{\left[\mathbf{m}^{2} / \mathbf{g}\right]}\end{array}$ & $\begin{array}{c}\mathbf{V}_{\mathbf{a}} \\
{\left[\mathbf{c m}^{3} / \mathbf{g}\right]}\end{array}$ \\
\hline HTT/08/25 & 27 & 0.127 & 175 & 0.279 \\
HTT/09/25 & 38 & 0.177 & 177 & 0.411 \\
HTT/10/25 & 131 & 0.468 & 236 & 0.759 \\
HTT/12/25 & 24 & 0.078 & 86 & 0.256 \\
\hline
\end{tabular}

Based on Table 2 it is clear that from the point of view of surface area, optimal $\mathrm{pH}$ for hydrotalcite preparation is 10. In Table 3, calculated specific surface areas of samples prepared at $\mathrm{pH} 10 \mathrm{can}$ be seen. The range of preparation temperature was from 25 to $55^{\circ} \mathrm{C}$ and after the preparation, samples were calcined at $150{ }^{\circ} \mathrm{C}$ and $450{ }^{\circ} \mathrm{C}$. It can be seen that the sample of HTT/10/35 synthesized at $35{ }^{\circ} \mathrm{C}$ shows the highest specific surface area compared to other samples.

However, in Figure 2 it can be seen that the synthesis temperature does not significantly affect

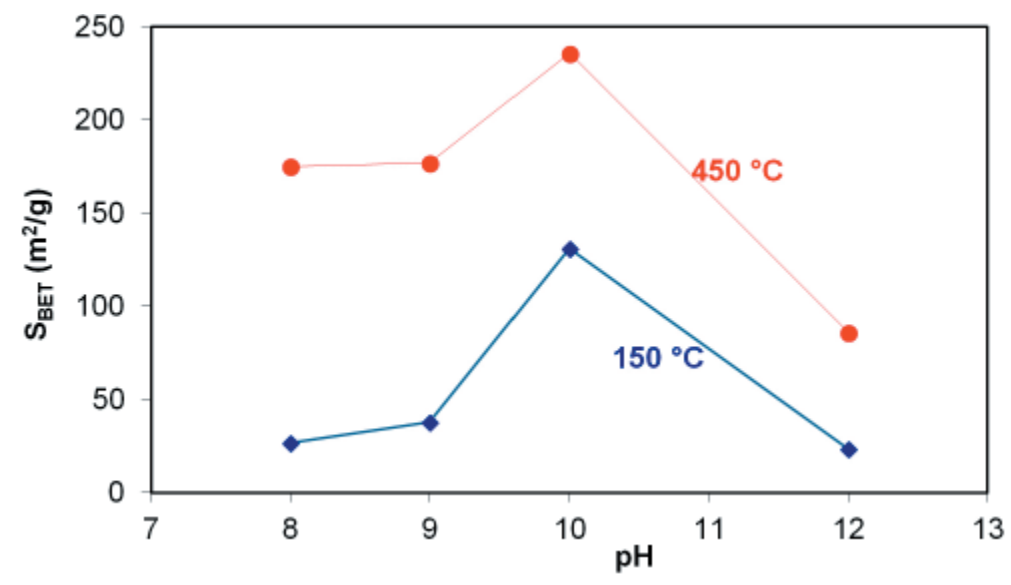

Fig. 1. Comparison of samples prepared with different $\mathrm{pH}$ calcined at $150{ }^{\circ} \mathrm{C}$ and $450{ }^{\circ} \mathrm{C}$.

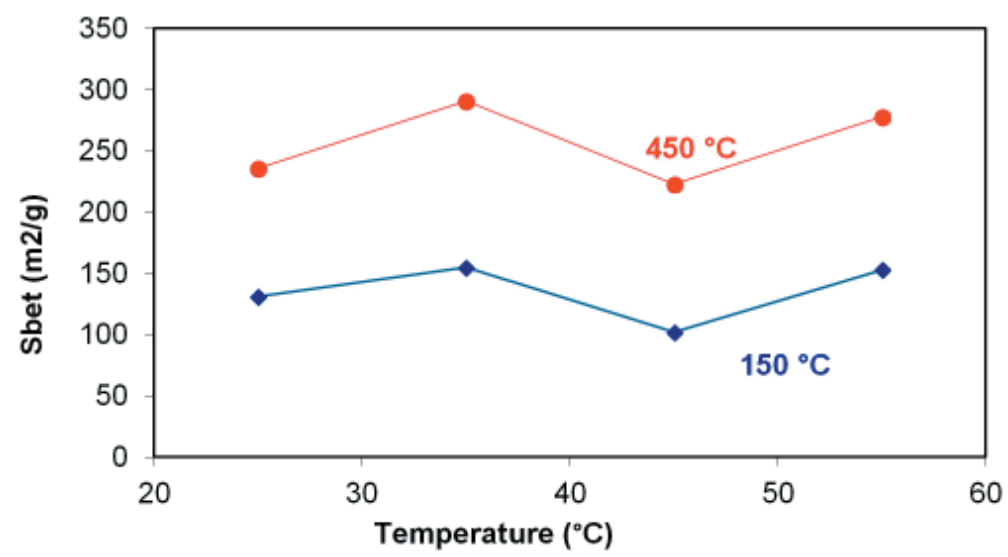

Fig. 2. Comparison of surface area of samples prepared at different synthesis temperatures and calcined at $150{ }^{\circ} \mathrm{C}$ and $450{ }^{\circ} \mathrm{C}$. 
Tab. 3. Determined surface area of samples with different preparation temperatures.

\begin{tabular}{lcccc}
\hline \multirow{2}{*}{ Sample } & \multicolumn{2}{c}{$\mathbf{1 5 0}^{\circ} \mathbf{C}$} & \multicolumn{2}{c}{$\mathbf{4 5 0}{ }^{\circ} \mathbf{C}$} \\
\cline { 2 - 5 } & $\begin{array}{c}\mathbf{S}_{\text {BET }} \\
{\left[\mathbf{m}^{2} / \mathbf{g}\right]}\end{array}$ & $\begin{array}{c}\mathbf{V}_{\mathrm{a}} \\
{\left[\mathbf{c m}^{3} / \mathbf{g}\right]}\end{array}$ & $\begin{array}{c}\mathbf{S}_{\text {BET }} \\
{\left[\mathbf{m}^{2} / \mathbf{g}\right]}\end{array}$ & $\begin{array}{c}\mathbf{V}_{\mathrm{a}} \\
{\left[\mathbf{c m}^{3} / \mathbf{g}\right]}\end{array}$ \\
\hline HTT/10/25 & 131 & 0.468 & 235 & 0.759 \\
$\mathbf{H T T} / \mathbf{1 0} / \mathbf{3 5}$ & $\underline{155}$ & 0.630 & $\underline{291}$ & 0.856 \\
$\mathbf{H T T} / \mathbf{1 0} / \mathbf{4 5}$ & 102 & 0.457 & 223 & 0.721 \\
$\mathbf{H T T / 1 0} / \mathbf{5 5}$ & 153 & 0.620 & 278 & 0.907 \\
\hline
\end{tabular}

the specific surface area of hydrotalcite; however, four samples are not enough to make a conclusion whether the preparation temperature affects the specific surface area at all.

\section{$X R D$}

Influence of preparation temperature and synthesis $\mathrm{pH}$ on hydrotalcite properties has been investigated also by X-ray diffraction. XRD patterns of samples prepared at constant calcination temperature of $450{ }^{\circ} \mathrm{C}$ and different preparation temperatures are shown in Figure 3. This calcination temperature was chosen because hydrotalcite layered structure changes to mixed metal oxides structure. Higher calcination temperatures caused destruction of the layered structure and led to the formation of spinel structure.

The XRD pattern shows typical peaks of mixed metal oxide structure consisting of a symmetrical and sharp peak with high intensity at low $2 \theta$ angle (8-10) and asymmetric broad peaks at high $2 \theta$ angle. These

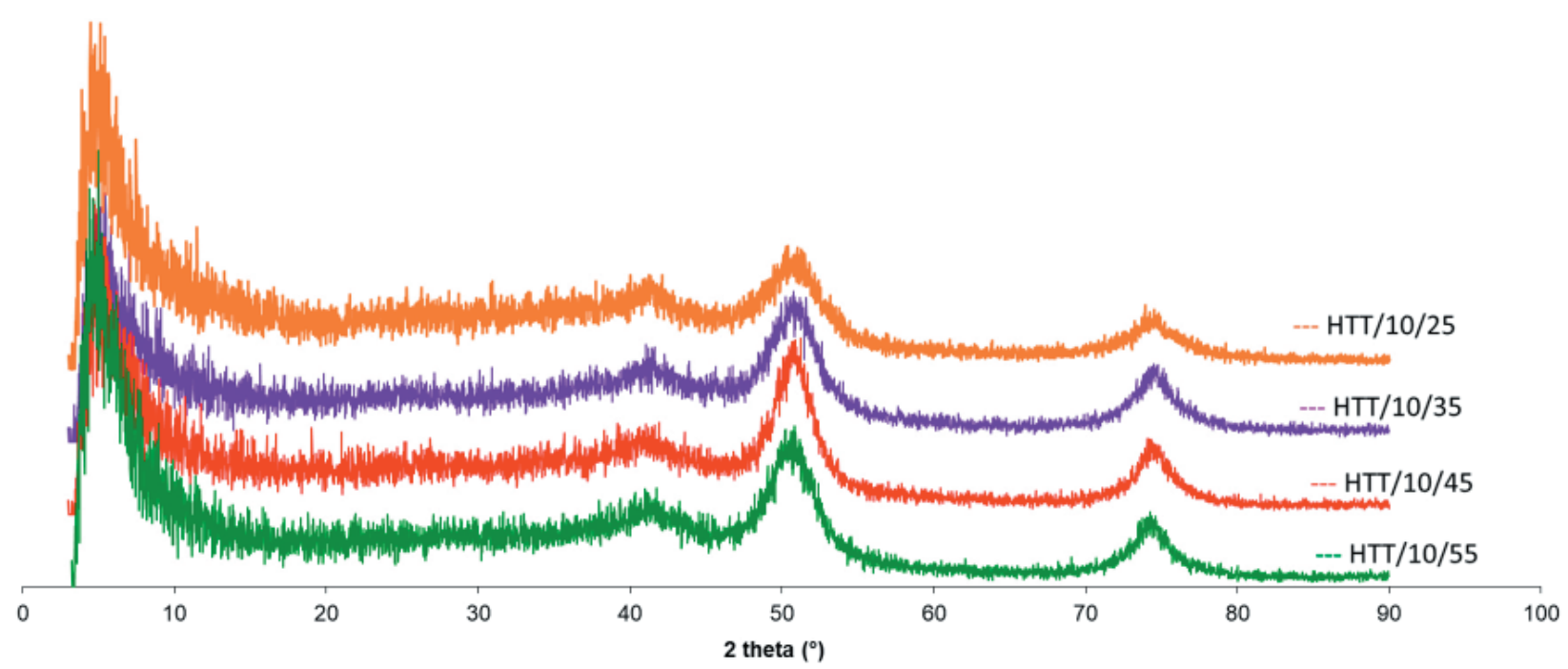

Fig. 3. XRD patterns of samples prepared at constant $\mathrm{pH}$ calcined at $450{ }^{\circ} \mathrm{C}$.

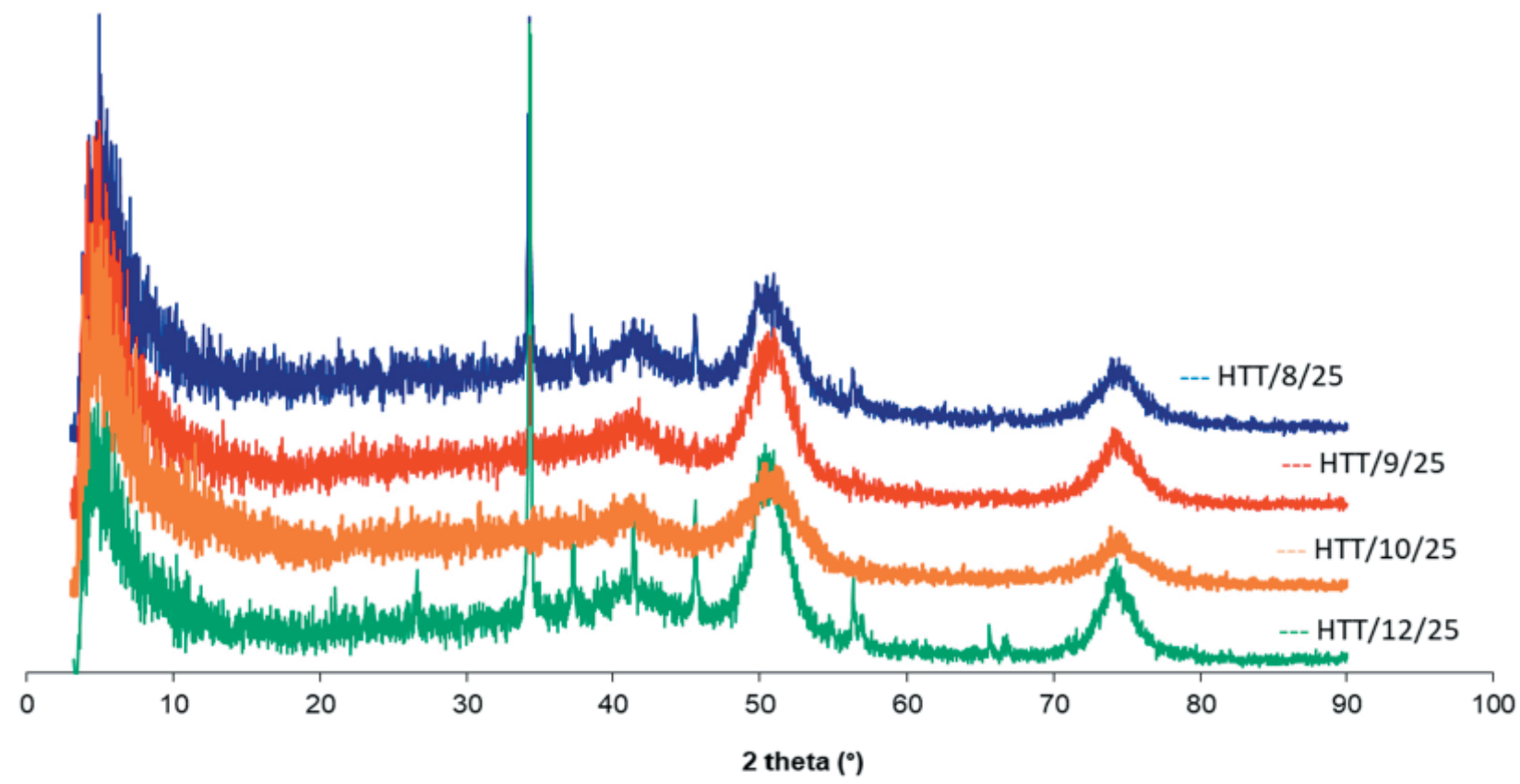

Fig. 4. XRD patterns of samples prepared at constant temperature and calcined at $450{ }^{\circ} \mathrm{C}$. 
diffraction patterns indicate good crystallinity of the prepared hydrotalcite (Wiyantoko et al., 2015). The influence of synthesis temperature on crystallinity is small which can be seen as just a little difference between the intensity of each peak.

In Figure 4, XRD pattern of samples prepared at constant temperature $\left(25^{\circ} \mathrm{C}\right)$ but different synthesis $\mathrm{pH}$ can be seen. Samples were calcined at the temperature of $450{ }^{\circ} \mathrm{C}$. The XRD pattern also shows typical peaks of mixed metal oxide structure. In the sample prepared at $\mathrm{pH} 12$, intense reflection at $2 \theta$ values of $35^{\circ}$ and several smaller reflections in the $2 \theta$ range of $25^{\circ}-70^{\circ}$ can be seen. These peaks can be attributed to $\mathrm{NaNO}_{3}$ crystals and their presence may be caused by insufficient sample washing during filtration. Filtration of HTT/12/25 (pH 12) is difficult probably due to the crystal size of the prepared sample. The influence of synthesis $\mathrm{pH}$ on the crystallinity of hydrotalcite is considerably higher than that of the preparation temperature. In the $2 \theta$ range from $30^{\circ}$ to $45^{\circ}$, there are not very intense peaks in samples HTT/08/25 and HTT/12/25 prepared at pH 8 and 12, which are not characteristic peaks for mixed oxides structure.

\section{SEM}

Based on XRD, differences between the sample crystals obtained under different preparation conditions are minimal. Crystallinity of the prepared samples was in line with the characteristic reflections from the XRD pattern. (Wiyantoko et al., 2015) Figure 5 shows a SEM image of HTT/10/25 prepared at $25^{\circ} \mathrm{C}$ and $\mathrm{pH} 10$, which proved to be the best preparation conditions. The image shows very thin crystals. The morphology of prepared hydrotalcite was formed by accumulation of nanoparticle aggregates (Wang et al., 2012).

\section{Adsorption-desorption isotherm}

The following graphs show the adsorption-desorption isotherms of samples calcinated at $150{ }^{\circ} \mathrm{C}$ and $450{ }^{\circ} \mathrm{C}$. Based on their shape, mesoporous texture of the samples can be seen. As a result of capillary condensation, a hysteresis loop is formed caused by a different mechanism of pores filling and emptying. These hysteresis loops are formed due to the presence of mesopores. Distribution of mesopores is in average $5-50 \mathrm{~nm}$, some are up to $70 \mathrm{~nm}$ when it comes to macropores. The volume of micropores was evaluated using the t-plot and it was found to be negligible; specific surface area of mesopores, $S_{t}$, was practically the same as $\mathrm{S}_{\mathrm{BET}}$. When comparing the effect of preparation temperature on the adsorption isotherm, the total pore volume is slightly increased in the sample prepared at $35^{\circ} \mathrm{C}$. The effect of calcination temperature can also be seen at greater pore volumes at higher calcination temperatures, which is positive for the catalyst properties.

\section{Temperature-programmed desorption of $\mathrm{CO}_{2}$ ( $\mathrm{TPD}-\mathrm{CO}_{2}$ )}

Hydrotalcite belongs to basic catalysts. With increasing basicity, catalytic properties of hydrotalcite are better. TPD- $\mathrm{CO}_{2}$ was used to determine basicity of all hydrotalcite samples calcinated at $450{ }^{\circ} \mathrm{C}$. As it can be seen in the previous section, after calcination at temperatures below $450{ }^{\circ} \mathrm{C}$, hydrotalcite structure changes from layered to mixed metal oxides. Table 4 shows calculated values based on $\mathrm{CO}_{2}$ desorption measurements. Sample prepared at pH 10 and at $35^{\circ} \mathrm{C}$ achieved the highest basicity. The strong basicity in mixed oxides is connected to the presence of alkaline metals. (Fraile et al., 2015).

In Figures 7 and 8, dependence of the measured signal from the calcination temperature can be

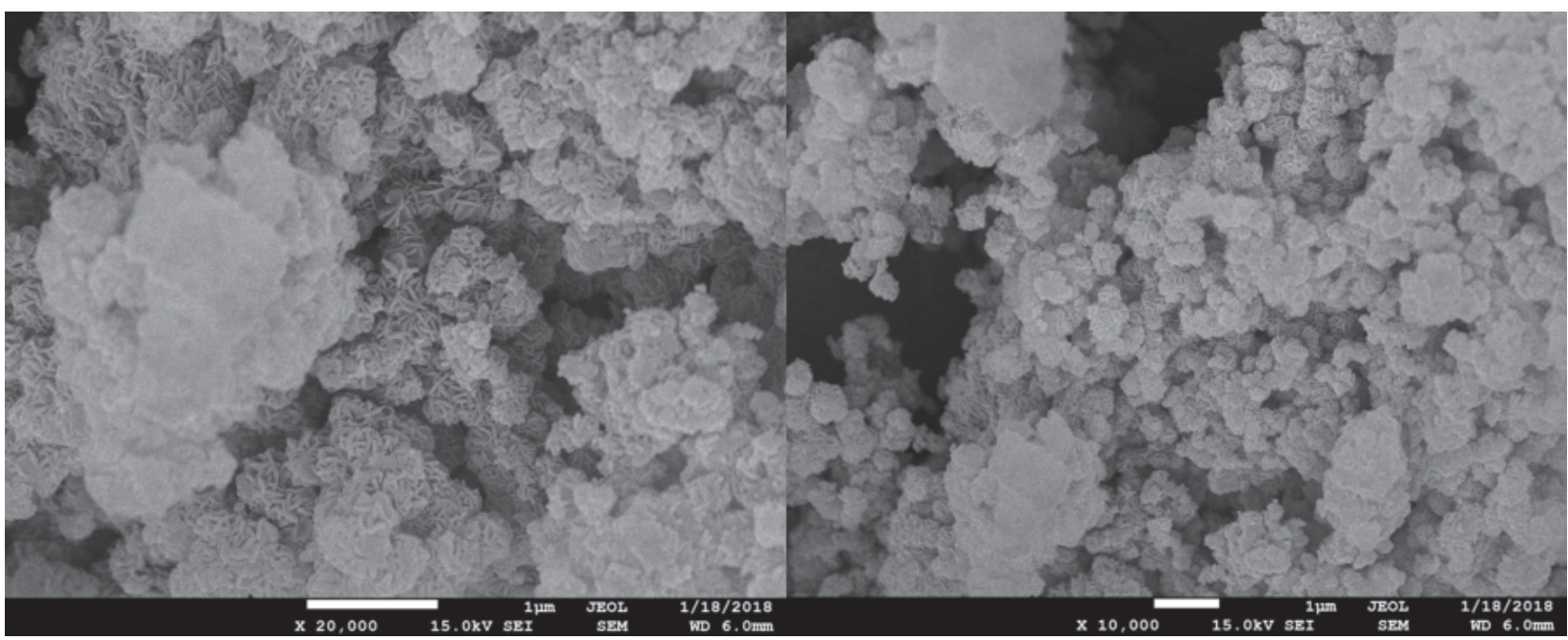

Fig. 5. SEM image of sample HTT/10/25 prepared at pH 10 and preparation temperature of $25^{\circ} \mathrm{C}$. 

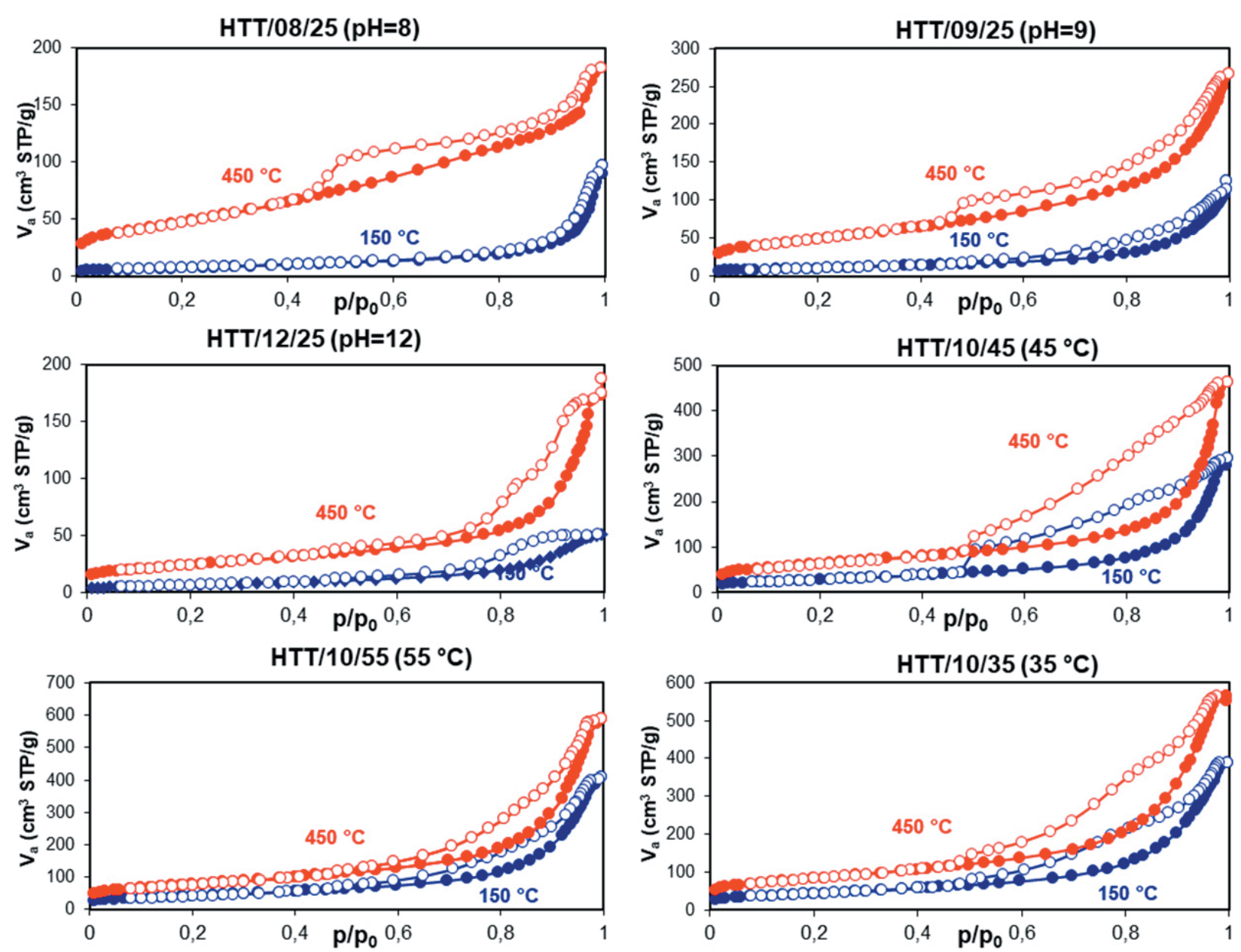

Fig. 6. Adsorption-desorption isotherms of prepared samples.

Tab. 4. Calculated values of basicity based on $\mathrm{CO}_{2}$ desorption measurements.

\begin{tabular}{lccccccc}
\hline Sample & HTT/10/25 & HTT/08/25 & HTT/09/25 & HTT12/25 & HTT/10/45 & HTT/10/55 & HTT/10/35 \\
\hline mmol CO$_{2} / \mathbf{g}$ & 1.04 & 1.35 & 1.10 & 0.92 & 0.78 & 1.38 & $\underline{1.44}$ \\
\hline
\end{tabular}

seen. Through the calcination of hydrotalcite, basic centers are formed. At temperatures below $100{ }^{\circ} \mathrm{C}$, weak basic centers are visible. At higher calcination temperatures, from $100{ }^{\circ} \mathrm{C}$ to $200{ }^{\circ} \mathrm{C}$, medium-basic sites, and at temperatures above $200{ }^{\circ} \mathrm{C}$, strong basic sites occur (Navajasa et al., 2018). The sample prepared at $\mathrm{pH} 8$ shows an intense maximum in the area of weak basic centers, which can be seen in Figure 7 . In contrast, the HTT/10/25 sample does not reach such high intensity as the HTT/08/25 sample, but its signal indicates the presence of medium-basic or strong basic sites. In case of preparation temperature effect on sample basicity, high maximum in sample HTT/10/35 can be seen in the area of weak basic center, but high signal at other temperatures indicates the presence of medium-weak and strong basic sites. In Table 4, a comparison of basicity of all samples is shown, sample HTT/10/35 has the highest basicity among all samples.

\section{Conclusion}

Because of its wide range of application and easy preparation, hydrotalcite is an interesting substance. Preparation of hydrotalcite at different preparation temperatures and $\mathrm{pH}$ values provides information on the influence to hydrotalcite properties. Preparation by co-precipitation is the most common method to prepare this catalyst with the required structure to catalyze basic reactions. Basicity of hydrotalcite is one of the key properties. Preparation $\mathrm{pH}$ can influence basicity as it can be seen for sample HTT/10/35 prepared at $\mathrm{pH} \mathrm{10,} \mathrm{where} \mathrm{basicity} \mathrm{reached} \mathrm{the} \mathrm{highest}$ value of all samples. In case of specific surface area, sample HTT/10/25 prepared at $\mathrm{pH} 10$ showed the highest surface area. Preparation temperature does not have any significant effect on the specific surface area. Hydrotalcite is a mesoporous material as indicated by the hysteresis loop. In case of samples 


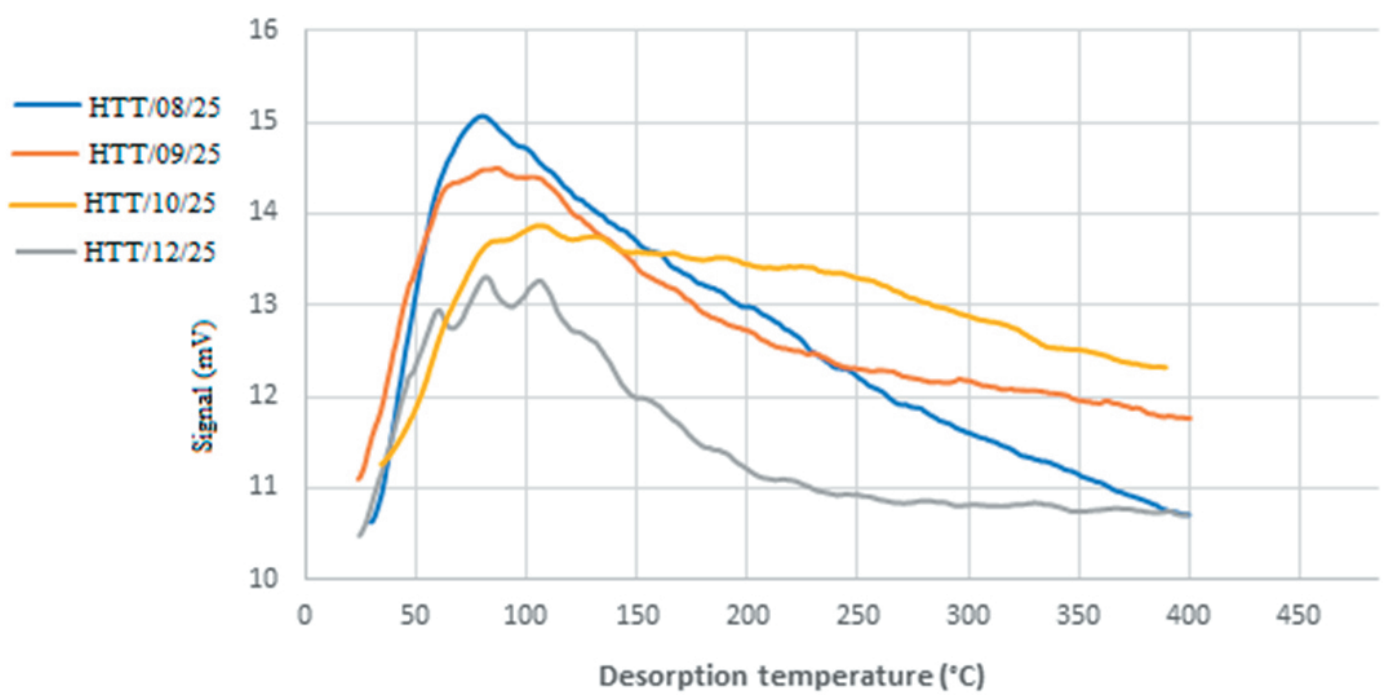

Fig. 7. Desorption curve of samples prepared at different pH.

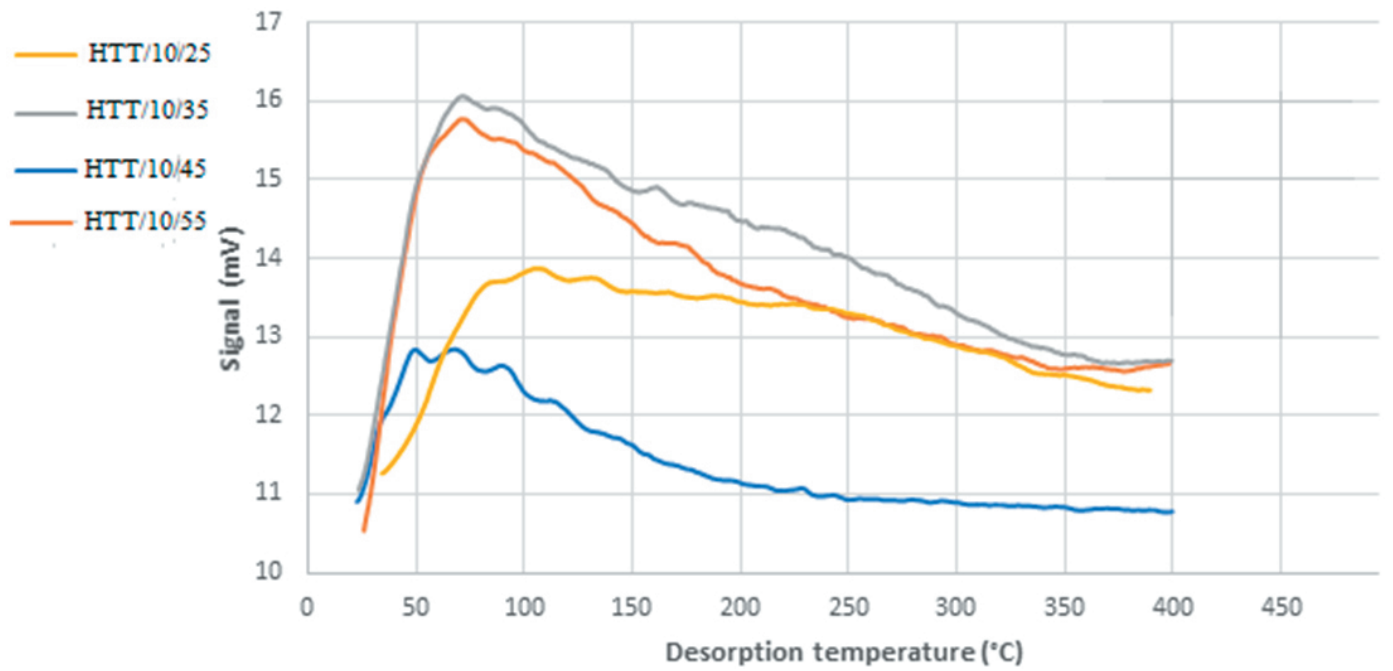

Fig. 8. Desorption curve of samples prepared at different temperatures.

prepared at $35^{\circ} \mathrm{C}$, higher pore volume can be seen. With higher pore volume, the sorption capacity of hydrotalcite increases, which is important when it is used as an adsorbent to reduce $\mathrm{NO}_{\mathrm{x}}$ and $\mathrm{SO}_{\mathrm{x}}$ emissions from industry. XRD patterns showed good crystallinity of prepared samples with peaks typical for mixed metal oxide structure. In sample HTT/12/25 prepared at $\mathrm{pH} 12$, high intensity peaks can be seen which was attributed to $\mathrm{NaNO}_{3}$ crystals present due to insufficient washing of sample during filtration.

\section{Acknowledgement}

This research has been financially supported by the Slovak Research and Development Agency under No. APVV-160097.

\section{References}

Fraile JM et al. (2015) The basicity of mixed oxides and the influence of alkaline metals: the case of transesterification reactions. Departamento de Química Orgánica. ICMA. C.S.I.C. 2015, Zv. Universidad de Zaragoza. Pedro Cerbuna 12, E-50009 Zaragoza (Spain).

Wiyantoko B et al. (2015) Synthesis and Characterization of Hydrotalcite at Different $\mathrm{Mg} / \mathrm{Al}$ Molar Ratios. Procedia Chemistry 17: 21-26.

Cavani F. et al. (1991) Hydrotalcite-type anionic clays: Preparation, properties and applications. Catalysis Today. 11: 173.

Bezerra DM et al. (2017) Structural, vibrational and morphological properties of layered double hydroxides containing $\mathrm{Ni}^{2+}, \mathrm{Zn}^{2+}, \mathrm{Al}^{3+}$ and $\mathrm{Zr}^{4+}$ cations. Materials Characterization. 2017, 29-36. 
Cavani F, Trifirb F, Vaccari A (1991) Hydrotalcite-type anlonlc clays: preparation, properties and applications. Catalysis Today. 173-301.

Muriithi GN et al. (2016) Synthesis and characterization of hydrotalcite from South African Coal fly ash. Powder Technology. 2. November 2016, 299-309.

Yang C, Liao L et al. (2016) Synthesis and characterization of $\mathrm{Mn}$ intercalated Mg-Al hydrotalcite. Journal of Colloid and Interface Science. 1. April 2016, 115-120.

Kloprogge1 JT, Frost RL (1999) Fourier Transform Infrared and Raman Spectroscopic Study of the Local Structure of Mg-, Ni-, and Co-Hydrotalcites. Journal of Solid State Chemistry. 506-515.

Pérez-Ramírez J et al. (2001) In situ Fourier transform infrared and laser Paman spectroscopic study of the thermal decomposition of $\mathrm{Co}-\mathrm{Al}$ and $\mathrm{Ni}-\mathrm{Al}$ hydrotalcites. Vibrational Spectroscopy. 75-88.

He J et al. (2005) Preparation of Layered Double Hydroxides. Struct Bond. 89-119.

Wiley J and sons, Kirk-Othmer Encyclopedia of Chemical Technology.

Jitianu M et al. (2000) IR structural evidence of hydrotalcites derived oxidic forms. Vibrational Spectroscopy. 75-86.

Kikhtyanin O, Tišler Z, Velvarská R, Kubička D (2016) Reconstructed Mg-Al hydrotalcites prepared by using different rehydration and drying time: Physicochemical properties and catalytic performance in aldol condensation. Applied Catalysis A: General. 19. December 2016, 85-96.
Salomão R et al. (2013) Hydrotalcite $\left(\mathrm{Mg}_{6} \mathrm{Al}_{2}(\mathrm{OH})_{16}\left(\mathrm{CO}_{3}\right)\right.$. . $4 \mathrm{H}_{2} \mathrm{O}$ ): A Potentially Useful Raw Material for Refractories. Interceram - refractories manual. 187.

Sato T et al. (1988) Synthesis of hydrotalcite-like compounds and their physico chemical properties. Reactivity of Solids. 219-228.

Nishimura S et al. (2013) Characterization, synthesis and catalysis of hydrotalcite-related materials for highly efficient materials transformations. Green Chemistry.

Basag S et al. (2016) Cu-Mg-Al hydrotalcite-like materials as precursors of effective catalysts for selective oxidation of ammonia to dinitrogen - The influence of $\mathrm{Mg} / \mathrm{Al}$ ratio and calcination temperature. Applied Clay Science. 4. March 2016, 122-130.

Baskaran T et al. (2015) Progress on layered hydrotalcite (HT) materials as potential support and catalytic materials. Royal society of chemistry. 26. September 2015.

Wang Q et al. (2012) Morphology and composition controllable synthesis of $\mathrm{Mg}-\mathrm{Al}-\mathrm{CO}_{3}$ hydrotalcites by tuning the synthesis $\mathrm{pH}$ and the $\mathrm{CO}_{2}$ capture capacity. Applied Clay Science. 18-26. 